\title{
Displasia renal em cão da raça Rotweiller
}

[Renal dysplasia in a dog breed Rotweiller]

\author{
F.S. Volkweis ${ }^{1}$, A.M.S. Almeida ${ }^{2}$, L. Wong $^{3}$ F. Mulinari ${ }^{4}$, H.L. Santos Júnior ${ }^{4}$ \\ ${ }^{1}$ Aluna de pós-graduação - União Pioneira de Integração Social - UPIS - Brasília, DF \\ ${ }^{2}$ Residente - União Pioneira de Integração Social - UPIS - Brasília, DF \\ ${ }^{3}$ Aluna de graduação - União Pioneira de Integração Social - UPIS - Brasília, DF \\ ${ }^{4}$ União Pioneira de Integração Social - UPIS - Brasília, DF
}

\begin{abstract}
RESUMO
Descreveram-se os achados clínicos e patológicos de um caso de displasia renal em um cão da raça Rotweiller com oito meses de idade. O animal apresentou vômitos, emagrecimento, polidpsia e poliúria. Houve elevação sanguínea de creatinina, cálcio e da fosfatase alcalina. À necropsia, notaram-se os rins diminuídos de tamanho, com estruturas císticas proeminentes sobre a superfície natural do órgão e, ao corte, firmes e com estruturas císticas distribuídas pelo parênquima. Na avaliação histológica, havia glomérulos imaturos, fibroplasia intersticial e dilatação cística tubular.
\end{abstract}

Palavras-chave: displasia, rim, Rotweiller

\begin{abstract}
In this study we describe the clinical and pathological findings of a case of renal dysplasia in a dog from the Rottweiler breed at 8 months of age. The animal presented vomiting, weight loss, polydipsia and polyuria. There was an increase of blood creatinine, calcium, and alkaline phosphatase. At necropsy it was noted that the kidneys were reduced in size, with prominent cystic structures on the natural surface of the body and the cutting and firm with cystic structures distributed throughout the parenchyma. The histological evaluation was immature glomeruli, interstitial fibroplasia and tubular cystic dilation.
\end{abstract}

Keywords: dysplasia, kidney, Rottweiler

\section{INTRODUÇÃO}

A displasia renal é uma enfermidade congênita caracterizada por alterações no desenvolvimento do parênquima renal durante o período embrionário (Pereira et al., 2007; Azizi et al., 2010). É uma enfermidade frequentemente relatada em cães das raças Shih-Tzu e Lhasa Apso (Hoppe et al., 1990), Golden Retriever (Kerlin e Winkle, 1995), Rodhesian (Lobetti et al., 1996), Bernese (Olenick, 1999), Boxer (Hoppe e Karlstam, 2000) e Mastiff (Abraham et al., 2003).

Em algumas raças, como, por exemplo, o ShihTzu, há uma possível relação na transmissão de um gene recessivo autossômico simples com o aparecimento da displasia renal (Brum et al., 2008). Os sinais clínicos relacionam-se à insuficiência renal crônica e incluem anorexia, letargia, poliúria, polidipsia e emagrecimento (Lucke et al., 1980; Brum et al., 2008). O hiperparatireoidismo secundário e consequente osteodistrofia fibrosa é um achado comum em cães acometidos pela doença (Brum et al., 2008).

$\mathrm{Na}$ avaliação histológica, visualizam-se no parênquima renal glomérulos rudimentares e atróficos, associados à dilatação e atrofia tubular cística (Lucke et al., 1980; Morton et al., 1990). Exames complementares, como ultrassonografia, bioquímico sérico e urinálise, auxiliam no diagnóstico da enfermidade (Hoppe et al., 1990; Green, 1996). Este trabalho tem como objetivo

Recebido em 29 de agosto de 2011

Aceito em 19 de julho de 2012

E-mail: fabisperb@hotmail.com 
descrever os achados clínicos e patológicos da displasia renal em cão da raça Rotweiller.

\section{RELATO DE CASO}

Um cão da raça Rotweiller, de oito meses de idade, apresentou vômitos, emagrecimento, polidipsia e poliúria. Ao exame clínico, revelou estado corporal ruim e mucosas ocular e oral acentuadamente esbranquiçadas. Foram realizados hemograma, bioquímico sérico (creatinina, cálcio e fosfatase alcalina) e ultrassonografias abdominal e pélvica. O resultado do hemograma apresentou anemia normocítica normocrômica. No bioquímico sérico, havia aumento da creatinina, $9,4 \mathrm{mg} / \mathrm{dL}$ (valor de referência 0,5 - 1,8mg/dL), cálcio, $12,3 \mathrm{mg} / \mathrm{dL}$ ( valor de referência $9-11 \mathrm{mg} / \mathrm{dL}$ ) e da fosfatase alcalina, 231,0U/L (valor de referência até $100 \mathrm{U} / \mathrm{L})$.

À ultrassonografia, foram visualizados os rins com contornos irregulares, falta de definição entre cortical e medular, hiperecogenicidade de parênquima renal e, no rim esquerdo, presença de cistos pelo parênquima (Fig. 1). Observou-se a vesícula urinária repleta de sedimento urinário anecoico, com presença de traços hiperecoicos.

O animal veio a óbito e foi encaminhado ao setor de patologia para necropsia. Ao exame macroscópico, observaram-se mucosas ocular e oral acentuadamente esbranquiçadas. Ambos os rins estavam diminuídos de tamanho, com estruturas císticas proeminentes sobre a superfície natural do órgão (Fig. 2). Ao corte, apresentavam-se firmes e com formações císticas variando de 0,2 a $0,5 \mathrm{~cm}$ de diâmetro, com líquido translúcido em seu interior (Fig. 3). Observaram-se aumento de volume e deformidade da mandíbula. A mucosa estomacal apresentava-se hiperêmica. Na pleura intercostal, havia áreas esbranquiçadas e lineares. Na íntima da aorta, notaram-se áreas circunscritas, firmes e elevadas. Os fragmentos dos órgãos foram coletados e fixados em formol $10 \%$, processados rotineiramente e corados com hematoxilina e eosina e tricrômico de Gomori, em alguns cortes renais.
Os achados histológicos revelaram túbulos renais dilatados, com epitélio cúbico ou achatado, associado à fibroplasia intersticial moderada. Notaram-se diminuição do tufo glomerular (atrofia glomerular) e espaços glomerulares dilatados com material eosinofílico e amorfo em sua luz (proteinúria) (Fig. 4). Havia infiltrado inflamatório mononuclear intersticial e deposição de material mixoide, ao qual a coloração especial pelo tricrômico de Gomori foi negativa para colágeno. Na mandíbula, visualizou-se rarefação óssea entremeada por deposição de um tecido fibrovascular focalmente extenso. Observaram-se edema pulmonar difuso e calcificação da parede de brônquios e bronquíolos. $\mathrm{Na}$ parede do estômago, havia deposição de material basofílico granular (mineralização), positiva para cálcio na coloração especial de Von Kossa.

\section{DISCUSSÃO}

A displasia renal é uma enfermidade caracterizada por distúrbios no desenvolvimento embrionário dos rins (Kerlin e Winkle, 1995; Hoppe e Karlstam, 2000; Ohara et al., 2001). Acomete animais jovens, com menos de dois anos de idade (Brum et al., 2008). Segundo Azizi et al. (2010), há evidências de fatores genéticos no aparecimento da enfermidade. $O$ cão do presente relato é da raça Rotweiller, com oito meses de idade. Na literatura há poucos relatos do acometimento de Rotweiller (Peeters et al., 2000).

Os sinais demonstrados pelo animal, como vômitos, emagrecimento, polidipsia e poliúria, são descritos por Lucke et al. (1980); Brum et al. (2008); Lagoa (2010). Segundo Hoppe e Karlstam (2000), esses achados clínicos estão relacionados com o desenvolvimento de insuficiência renal crônica, e a severidade dos sinais depende do grau de lesão renal.

Os exames laboratoriais revelaram anemia arregenerativa, creatinina elevada, além da hipercalcemia, corroborando com Lucke et al. (1980) e Hoppe et al. (1990). A anemia arregenerativa decorre da baixa produção de eritropoetina por um rim acometido pela enfermidade (Hünning et al., 2009). 


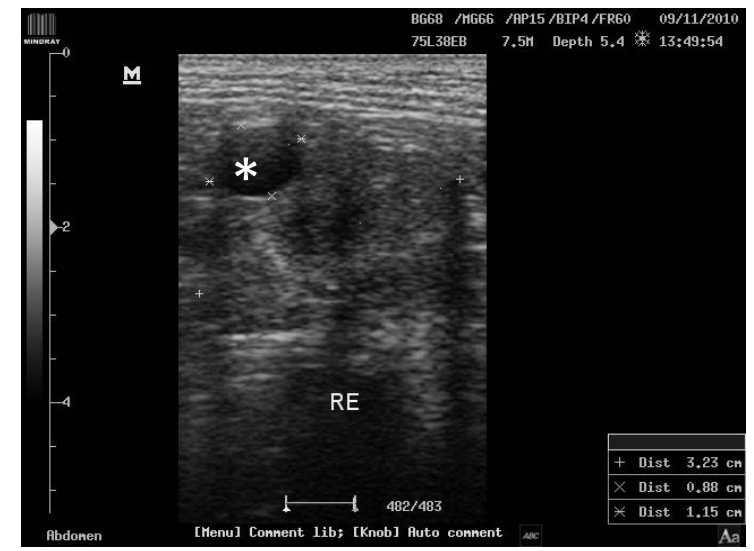

Figura 1. Ultrassonografia evidenciando a presença de estrutura cística $(*)$ no parênquima renal.

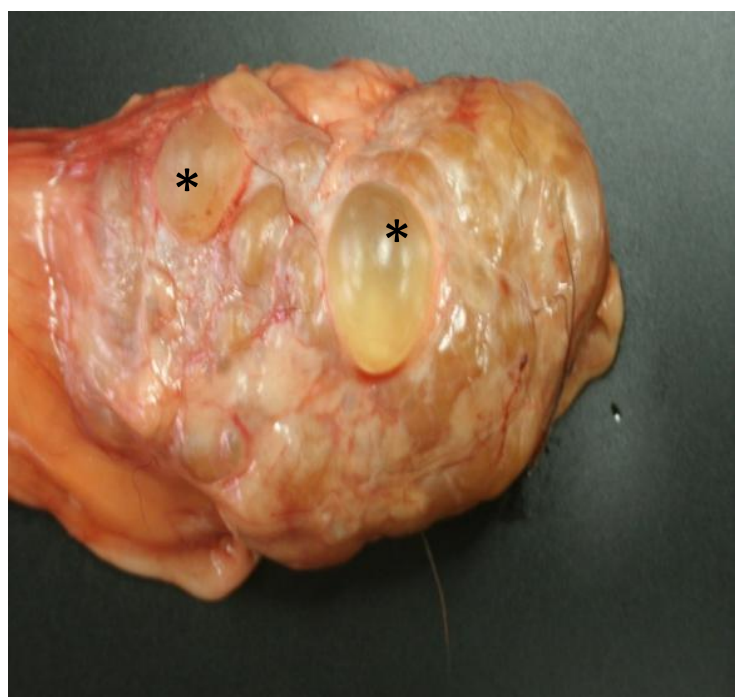

Figura 3. Rim: superfície irregular associada a formações císticas (*) que sobrepassam a superfície natural do órgão.

O hiperparatireoidismo é decorrente da insuficiência renal crônica, resultando em aumento do paratormônio e incremento da reabsorção óssea (Matos et al., 2008). A retirada da matriz óssea tem como consequência a deposição de um tecido fibrovascular, elevação da concentração de cálcio sanguíneo e calcificação metastática (Gross, 1997; Brum et al., 2008). A hipercalcemia do animal foi confirmada pela avaliação sérica. A rarefação óssea associada à deposição de um tecido fibrovascular foi observada na mandíbula, resultando na deformidade constatada ao exame macroscópico, porém não havia perda ou

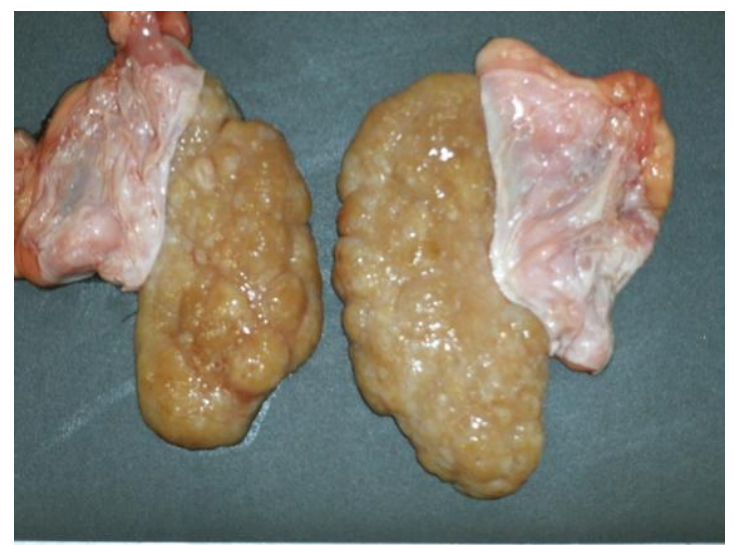

Figura 2. Rim: superfície irregular.

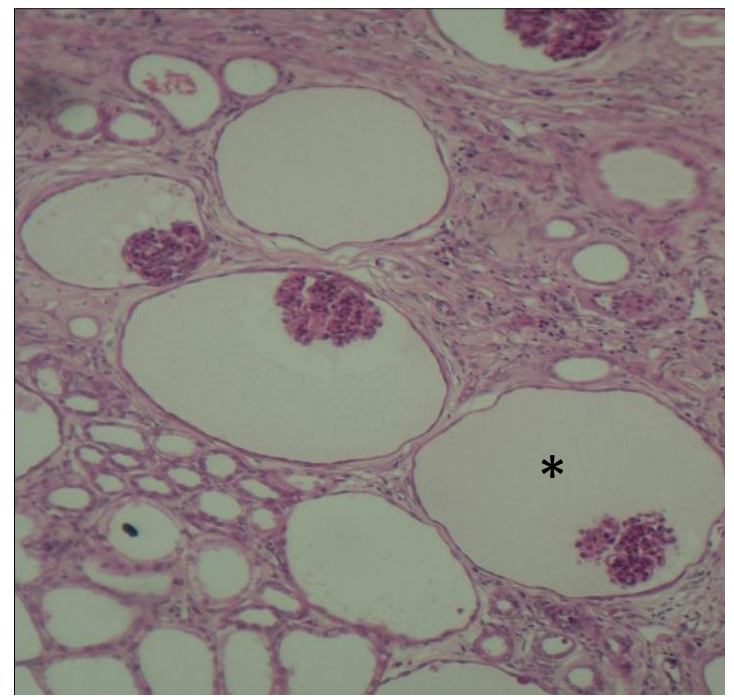

Figura 4. Rim: micrografia evidenciando atrofia glomerular e dilatação cística do espaço de Bowman (*) (HE, 40X).

distorções da arcada dentária do animal. Concentração sanguínea da fosfatase alcalina relaciona-se à extensão da reabsorção óssea (Lacativa et al., 2003). Neste animal, o hiperparatireoidismo aumentou a reabsorção óssea.

No exame ultrassonográfico, foram visualizados aumento da ecogenicidade renal e diminuição dos limites corticomedular, o que foi descrito como alterações característica da displasia renal por Green (1996) e Vac (2004). 
$\mathrm{Na}$ avaliação macroscópica, os achados confirmam os resultados de Lobetti et al. (1996) e Ohara et al. (2001), que descreveram perda da delimitação corticomedular, formações císticas e apresentam-se firmes à palpação. Outros achados incluíram calcificação de tecidos moles. Esta calcificação é decorrente da elevação dos níveis de cálcio sanguíneos e da deposição deste no tecido (calcificação metastática) (Gross, 1997).

$\mathrm{Na}$ histopatologia dos rins, confirmaram-se os achados relatados por Kerlin e Winkle (1995) e Morton et al. (1990), em que se visualizaram principalmente glomérulos imaturo, dilatação cística do espaço glomerular e túbulos, além da deposição de tecido conjuntivo intersticial e da presença de mesenquimal primitivo. Estes achados também são descritos por Azizi et al. (2010), em um felino.

\section{REFERÊNCIAS}

ABRAHAM, L.; BECK, C.; SLOCOMBE, R.F. Renal dysplasia and urinary trat infection in a Bull Mastiff Puppy. Australian Vet. J., v.81, p.336- 339, 2003.

AZIZI, S.; KHEIRANDISH, R.; YAZDANPOUR, H. Histopathologic features of a unilateral renal dysplasia in a cat (Felis domestica). Comp. Clin. Pathol., v.19, p.445-447, 2010.

BRUM, K.B.; JULIANO, R.S.; SOUZA, M.A. et al. Renal dysplasia in a boxer dog: Case report. Arq. Bras. Med. Vet. Zootec., v.60, p.1084-1088, 2008.

GREEN, R.W. Kidneys. In: GREEN, R.W. Small Animal Ultrasound. Philadelphia:Lippincott-Raven, 1996. p.197-210.

GROSS, T.L. Calcinosis circunscripta and renal dysplasia in a dog. Vet. Dermat., v.8, p.27-32, 1997.

HOPPE, A.; KARLSTAM, E. Renal Dysplasia in boxers and finish harriers. J. Small Anim. Pract., v.41, p.422-426, 2000.

HOPPE, A.; SWENSON, L.; JONSSON, L.; HEDHAMMAR, A. Progressive nephropathy due to renal Dysplasia in shitzu sogs in Swenden: A clinical pathological and genetic study. J. Small Anim. Pract., v.31, p.83-91, 1990.

HÜNNING, P.S.; AGUIAR, J.; LACERDA, L.A. et al. Displasia renal em um cão. Acta Scient. Vet., v.37, p.73-77, 2009.
KERLIN, R.L.; WINKLE, V.T.J. Renal Diplasia in Golden Retrievers. Vet. Pathol., v.32, p.327-329, 1995.

LACATIVA, P.G.S.; PATRICIO FILHO, P.J.M.; GONCALVES, M.D.C.; FARIAS, M.L.F. Indicações de paratireoidectomia no hiperparatireoidismo secundário à insuficiência renal crônica. Arq. Bras. Endocrinol. Met., v.47, p.644-653, 2003.

LAGOA, L.M.N.S. Nefropatia juvenil canina. 2010. 110f. Dissertação (Mestrado em Medicina Veterinária) - Universidade Técnica de Lisboa, Portugal.

LOBETTI, R.G.; PEARSON, J.; JIMENEZT, M. Renal dysplasia a Rhodesian ridgeback dog. J. Small Anim. Pract., v.37, p.552-555, 1996.

LUCKE, V.M.; KELLY, D.F.; DARKE, D.F. et al. Chronic renal failure in young dogs- possible renal dysplasia. J. Small Anim. Pract., v.21, p.169-181, 1980.

MATOS, J.P.S.; SAMPAIO, E.A.; LUGON, J.R. Modalidade de diálise e o controle de hiperparatireoidismo secundário. J. Bras. Nefrol., v.30, p.23-26, 2008.

MORTON, L.D.; SANECKDI, R.K.; GORDON. E. et al. Juvenile Renal Disease in Miniature Schnauzer Dogs. Vet. Pathol., v.27, p.455-458, 1990.

OHARA, H.; KOBAYASHI, Y.; TSUCHIYA, N. et al. Renal Displasia in a Shith tzu dog in Japan. J. Vet. Med. Science, v.63, p.1127-1130, 2001.

OLENICK, C.L. Congenital renal dysplasia and psycogenic polydipsia in a Bernese Mounthain dog. Canadian Vet. J., v.40, p.425-426, 1999.

PEETERS, D.; CLERCX, C.; MICHIELS, L. et al. Juvenile nephropathy in a Boxer, a Rottweiler, a Collie and an Irish Wolfhound. Australian Vet. J., v.78, p.162-165, 2000.

PEREIRA, G.Q.; PAULA, D.S.; NEGASSHIMA, J.K. et al. Displasia Renal em cão. Acta Scient. Vet., v.35, p.583-585, 2007.

VAC, M.H. Sistema Urinário: Rins, Ureteres, Bexiga Urinária e Uretra. In: CARVALHO, C.F. Ultrasonografia em Pequenos Animais. Roca: Rio de Janeiro, 2004. Cap.10. p.111-146. 